\title{
Blood cells transcriptomics as source of potential biomarkers of articular health improvement: effects of oral intake of a rooster combs extract rich in hyaluronic acid
}

\author{
Juana Sánchez • M. Luisa Bonet - Jaap Keijer - Evert M. van Schothorst • \\ Ingrid Mölller · Carles Chetrit · Daniel Martinez-Puig • Andreu Palou
}

Received: 26 February 2014 / Accepted: 2 July 2014/ Published online: 15 July 2014

(c) Springer-Verlag Berlin Heidelberg 2014

\begin{abstract}
The aim of the study was to explore peripheral blood gene expression as a source of biomarkers of joint health improvement related to glycosaminoglycan (GAG) intake in humans. Healthy individuals with joint discomfort were enrolled in a randomized, double-blind, placebo-controlled intervention study in humans. Subjects ate control yoghurt or yoghurt supplemented with a recently authorized novel food in Europe containing hyaluronic acid $(65 \%)$ from rooster comb (Mobile $\mathrm{e}^{\mathrm{TM}}$ as commercial name) for 90 days. Effects on functional quality-of-life parameters related to joint health were assessed. Whole-genome microarray analysis of peripheral blood samples from a subset of 20 subjects (10 placebo and 10 supplemented) collected pre- and postintervention was performed. Mobilee ${ }^{\mathrm{TM}}$ supplementation reduced articular pain intensity and synovial effusion
\end{abstract}

Electronic supplementary material The online version of this article (doi:10.1007/s12263-014-0417-3) contains supplementary material, which is available to authorized users.

J. Sánchez · M. L. Bonet · A. Palou ( $₫)$

Laboratory of Molecular Biology, Nutrition and Biotechnology (Nutrigenomics), University of the Balearic Islands and CIBER

Fisiopatología de la Obesidad y Nutrición (CIBEROBN), Edifici

Mateu Orfila. Carretera de Valldemossa Km 7.5,

07122 Palma de Mallorca, Spain

e-mail: andreu.palou@uib.es

J. Keijer - E. M. van Schothorst

Department of Human and Animal Physiology, Wageningen

University, Wageningen, The Netherlands

I. Mölller

Instituto Poal de Reumatologia, Barcelona, Spain

C. Chetrit · D. Martinez-Puig

Bioiberica S.A., Palafolls, Barcelona, Spain and improved knee muscular strength indicators as compared to placebo. About 157 coding genes were differentially expressed in blood cells between supplemented and placebo groups post-intervention, but not pre-intervention $(p<0.05$; fold change $\geq 1.2)$. Among them, a reduced gene expression of glucuronidase-beta (GUSB), matrix metallopeptidase 23B (MMP23B), xylosyltransferase II (XYLT2), and heparan sulfate 6-Osulfotransferase 1 (HS6ST1) was found in the supplemented group. Correlation analysis indicated a direct relationship between blood cell gene expression of $M M P 23 B$, involved in the breakdown of the extracellular matrix, and pain intensity, and an inverse relationship between blood cell gene expression of HS6ST1, responsible for 6-O-sulfation of heparan sulfate, and indicators of knee muscular strength. Expression levels of specific genes in blood cells, in particular genes related to GAG metabolism and extracellular matrix dynamics, are potential biomarkers of beneficial effects on articular health.

Keywords Blood cells · Transcriptomics · Joint discomfort $\cdot$ Glycosaminoglycans $\cdot$ Mobilee $^{\mathrm{TM}}$

\section{Introduction}

Degenerative joint disease (osteoarthritis, OA) is an important, highly prevalent health problem (Goldring and Goldring 2007; Das and Farooqi 2008; Bonet et al. 2011). Osteoarthritis (OA) is a heterogeneous disease characterized by the degradation of articular cartilage, subchondral bone alterations, and inflammation of the synovial membrane (Goldring and Goldring 2007; Das and Farooqi 2008). Osteoarthritis (OA) is a chronic and slowly 
progressive disease. However, prior to the onset of OA, there is a preclinical condition characterized by joint discomfort in which no structural lesions are apparent that may or may not progress to OA (Das and Farooqi 2008). Intervention at this stage appears to be of great importance as a target for functional health claims made on food.

The glycosaminoglycan (GAG) hyaluronic acid (HA) is used in the therapeutics of OA, mostly following intraarticular injection (Dougados et al. 1993; Altman and Moskowitz 1998). Recently, however, beneficial effect of HA following oral administration has been also demonstrated (Tashiro et al. 2012; Martinez-Puig et al. 2013). In fact, there is evidence that high-molecular-weight HA is absorbed and distributed to connective tissues after its oral administration (Balogh et al. 2008). In addition, oral supplementation with HA (as Mobilee ${ }^{\mathrm{TM}}$ formulation) reduced the degree of synovial effusion and increased the concentration of HA in synovial fluid in horses diagnosed with osteochondritis (Martínez-Puig et al. 2007). Moreover, a placebo-controlled nutritional study confirmed in humans that 3-month oral administration of HA (as Mobilee $^{\mathrm{TM}}$ ) provides improvement in knee muscle strength in individuals with mild joint discomfort (Martinez-Puig et al. 2013).

Despite the increasing prevalence of OA, early and readily accessible biomarkers that can be used in disease or pre-disease states prognosis and monitoring and/or as tools to evaluate the responsiveness to treatments are still lacking. This is an active area of research, and several potential biomarkers are currently at various stages of qualification and validation, including circulating or urinary levels of certain OA-related proteins or protein-degradation products such as cartilage oligomeric matrix protein (COMP), C-terminal cross-linked type I or type II collagen (CTX-I and CTX-II), type 2 Coll2-1, myeloperoxidase, or matrix metalloproteinase-3, among others (reviewed in (Kraus et al. 2011; Rousseau and Garnero 2012; Ramonda et al. 2013)).

Blood cells are increasingly being investigated as a noninvasive source of biomarkers of health/disease, nutritional exposure, and response to therapy. In fact, the expression levels of specific genes in blood cells have been proposed as markers of body metabolic status, potentially providing an early warning of future disorders (Sanchez et al. 2012). However, its potential relevance in the area of preclinical articular health or comfort has not been explored so far. Here, we aimed to explore the feasibility of using total human blood RNA as a source of biomarkers of articular health improvement related to Mobile $^{\mathrm{TM}}$ intake. Mobilee ${ }^{\mathrm{TM}}$ is a rooster comb extract containing HA (65\%), polysaccharides, and collagen, recently authorized as a novel food in Europe (EFSA 2013).

\section{Materials and methods}

Subjects

\section{Inclusion criteria}

- Adults of both sexes aged between 20 and 70 .

- Mild joint discomfort (visual analog scale (VAS) between 3 and $5 \mathrm{~cm}$ ).

- Symptomatic joint discomfort for a minimum of 6 months.

\section{Exclusion criteria}

- Subjects who have clinical OA or any other degenerative joint disease.

- Subjects receiving treatment with anti-inflammatory or chondroprotective drugs (chondroitin sulfate, glucosamine, HA, diacerein) 2 weeks before the selection.

- Subjects receiving intra-articular injections of the knee joint in the 3 months prior to the study.

- Subjects with cardiovascular, hepatic, renal, respiratory, or hematologic illness, or other medical or psychiatric condition that, in the opinion of the investigator, would compromise participation or be likely to lead to hospitalization during the course of the study.

\section{Study design}

The study was a double-blind, prospective nutritional intervention study carried out in accordance with the principles of the Declaration of Helsinki. All the participants gave their informed consent for the study, and the Fundació Gol i Gurina Ethical Review Committee approved the study protocol.

Between September 2009 and March 2010, subjects met all inclusion criteria and none of the exclusion criteria were randomly assigned to one of two experimental groups. The supplemented group ate one yoghurt supplemented with $80 \mathrm{mg}$ of Mobilee ${ }^{\mathrm{TM}}$ (Bioiberica S.A., Palafolls, Spain) per day for a period of 90 days. The stability of HA in the yoghurt matrix for a period of 4 weeks was assessed before the beginning of the study. The control group ate one yoghurt per day without any supplement. Subjects were told not to take analgesics or nonsteroidal anti-inflammatory drugs. Only paracetamol $(500 \mathrm{mg})$ was allowed as a pain reliever. Physical therapy was not carried out during the study period. The subjects that fulfilled the inclusion criteria without presenting any exclusion criteria were entered into a randomization scheme for the administration of supplemented or unsupplemented yoghurt. 
Subjects were assigned to treatment by a sequential randomization schedule in blocks of 4 following the confirmation of eligibility, before study yoghurts were provided. Randomization was performed and maintained by an independent statistician. The study yoghurts were provided in kits containing a randomization code. The sponsor, the investigator, and all study staff having a role in the day-today conduct of the study remained blinded to treatment.

\section{Clinical assessment}

Clinical assessment was documented by the same investigator for every subject during the whole study. Clinical assessment included the following criteria:

- Primary efficacy assessment: isokinetic test. The evaluation was carried out with a Biodex system 3 Pro Isokinetic dynamometer (Biodex Medical Systems, New York, USA) using five repetitions at two angular velocities $(180 \%$ s and $\left.240^{\circ} / \mathrm{s}\right)$. The subject assumed a sitting position with the hips flexed at $90^{\circ}$. The degree of freedom of the knee was restricted to extension/flexion of $0^{\circ}-0^{\circ}-90^{\circ}$. A break of 2 min was allowed between sets. Based on the data retrieved from all the sets, the maximum work load $(\mathrm{J})$, maximum peak torque $(\mathrm{Nm})$, and power $(\mathrm{W})$ at $180 \%$ s and $240 \%$ s were determined. The maximum peak torque $(\mathrm{Nm})$ was defined as the maximum force produced by the tested musculature at the two different angular velocities.

- Secondary efficacy assessments: ultrasonographic evaluation of the knee. A rheumatologist (medical specialist) performed ultrasonography of the study knee according to the prespecified ultrasonography parameters (details in (D'Agostino et al. 2005)). In addition, pain was assessed using the VAS.

- Other secondary efficacy parameters include overall quality-of-life assessment with subscales using the SF36 survey (McHorney et al. 1993).

The clinical data, pain assessment using the VAS, and inclusion/exclusion criteria were obtained at the selection visit. The selected participants were randomly distributed and given the isokinetic test, US evaluation, and SF-36 survey at the inclusion visit, 1 day prior to the consumption of the first yoghurt. The US evaluation, pain assessment, and SF-36 survey were repeated in weeks 4 and 8 after the start of the nutritional intervention period. At the end of the study (12 weeks), a complete clinical assessment was repeated, including a global subject-satisfaction assessment.

Blood sampling and processing for gene expression analysis

For each participant, a total of $2.5 \mathrm{~mL}$ peripheral blood was collected under fasting conditions into PAXgene vacutainer tubes (Qiagen, Izasa-Barcelona, Spain) via antecubital fossa venipuncture. PAXgene tubes contain a proprietary reagent that immediately stabilizes RNA, thus reducing RNA degradation and minimizing changes in gene expression following phlebotomy (Rainen et al. 2002). After the blood was drawn, the tubes were inverted 20 times, allowed to sit for $2 \mathrm{~h}$ at room temperature, and then stored at $-70{ }^{\circ} \mathrm{C}$ until processed. Total RNA was isolated using the PAXgene blood RNA kit according to the manufacturer's instructions (Qiagen). The RNA that is isolated with this protocol comes from all cells in whole blood. RNA quality and purity were analyzed by spectrophotometry using the Nanodrop ND-1000 (NanoDrop Techonologies, Inc., Wilmington, DE), and its integrity was measured on an Experion ${ }^{\mathrm{TM}}$ system using RNA StdSens chips (Bio-Rad, Madrid, Spain) just before microarray processing.

\section{Microarray processing}

Whole-genome microarray analysis of blood samples from a subset of 20 subjects (11 placebo and 9 supplemented) collected pre- and post-intervention was conducted. Samples were randomly selected ensuring an equal distribution between groups and that, for each subject, paired pre- and post-intervention mRNA samples of high quality were available (amount, purity, and integrity). For microarray hybridization, $1 \mu \mathrm{g}$ of RNA from each sample was reversetranscribed to complementary DNA (cDNA) using the Agilent Quick Amp Labeling kit (Agilent Technologies, Inc., CA, USA), according to the manufacturer's protocol. Thereafter, cDNA samples were split into 2 equal amounts, to synthesize Cyanine 3-CTP (Cy3)- and Cyanine 5-CTP (Cy5)-labeled cRNA as described previously (van Schothorst et al. 2007). Transcription and labeling were carried out at $40{ }^{\circ} \mathrm{C}$ for $2 \mathrm{~h}$. Labeled cRNA was purified using Qiagen Rneasy MiniSpin columns (Qiagen, Venlo, the Netherlands). The incorporation of dyes and cRNA concentration was measured using the "microarray measurement mode" of the NanoDrop ND 1000 spectrophotometer. About 2,500 ng of every Cy3-labeled cRNA sample (with a yield $\geq 825 \mathrm{ng}$ and activity $\geq 6.0$ pmol per $\mu \mathrm{g}$ cRNA) was pooled, and the pool was used as a common internal reference. One of the samples (from placebo preintervention group) did not reach the standard quality parameters at this stage and was excluded. Thus, hybridization was conducted with a total number of 39 samples. Individual samples containing $825 \mathrm{ng}$ of Cy5-labeled cRNA and $825 \mathrm{ng}$ of the Cy3-labeled cRNA pool were hybridized on $4 \times 44 \mathrm{~K}$ G4845A human whole-genome Agilent microarrays (Agilent Technologies, Inc., Santa Clara, CA, USA) for $17 \mathrm{~h}$ at $65^{\circ} \mathrm{C}$ in hybridization chambers in an oven rotating at $10 \mathrm{rpm}$ (Agilent 
Technologies). After hybridization, the arrays were washed with "GE wash buffer 2 " for $1 \mathrm{~min}$ at $37{ }^{\circ} \mathrm{C}$, followed by acetonitrile for $10 \mathrm{~s}$ at room temperature, and finally with a solution for stabilization and drying for $30 \mathrm{~s}$ at room temperature, according to the manufacturer's protocol (Agilent Technologies).

\section{Microarray data analysis}

The arrays were scanned with an Agilent Microarray Scanner (Agilent Technologies). Scanned images were examined for visible defects and proper grid alignment. The intensities of the signals from each spot were quantified, and the raw data were extracted using Feature Extraction Software version 10.5.1.1 (Agilent Technologies). Quality control was performed for each of the arrays using LimmaGUI package in $\mathrm{R}$ from Bioconductor Software version 2.1. All the arrays passed quality control based on MA plot and signal intensity distribution (Allison et al. 2006). Thus, in total, dataset from 39 arrays passed to the next step of analysis. Data were exported into GeneMaths XT 2.12 (Applied Maths, Sint-Martens-Latem, Belgium) for background correction and normalization. Locally weighted linear regression (lowess) analysis was chosen as a normalization method, which enables intensity-dependent effects in the $\log 2$ (ratio) values to be removed (Yang et al. 2002). Then, the values were converted to $\log 2$ values, and the target samples (Cy5) intensities were normalized against the intensities of reference samples ( $\mathrm{Cy} 3)$, as described previously (Pellis et al. 2003). To search for biomarkers in articular health, single $t$ test comparisons were performed. We focused only on those genes differentially expressed in peripheral blood between supplemented and placebo groups post-intervention, without pre-intervention differences. The threshold of significance for this statistical test was set at $p \leq 0.05$. Fold change (FC) calculation between both groups (supplemented vs. placebo subjects) was performed by exponential conversion of the signal log ratio; FC equals the gene expression ratio between supplemented and placebo in the case of increase and $-1 /$ this ratio, in the case of decrease. Subsequently, a computer-generated list of genes ( $p<0.05$ and absolute fold change $\geq 1.2$ ) was manually analyzed for their biological information, obtained with the use of available databases (NCBI-Gene and Medline-, Genecards and UniProt) based on key biological domains, such as molecular function and biological process.

Real-time quantitative RT-PCR analysis

To validate microarray data, mRNA expression levels of glucuronidase-beta (GUSB), matrix metallopeptidase 23B (MMP23B), xylosyltransferase II (XYLT2), and heparan sulfate 6-O-sulfotransferase 1 (HS6ST1) were measured by
RT-qPCR in blood cells. Quantitative RT-PCR was performed as previously described (Sanchez et al. 2009). The threshold cycle $(\mathrm{Ct})$ was calculated using the instrument's software (StepOne Software version 2.2), and the relative expression ratio of a target gene was calculated based on the corresponding real-time PCR efficiency and $\mathrm{Ct}$ deviation of an unknown sample versus mean $\mathrm{Ct}$ of all samples and expressed in comparison with a reference gene (Pfaffl 2001). Ribosomal protein, large, P0 (RPLPO) was chosen as reference gene because it has been validated for human studies (Dheda et al. 2004; Sanchez et al. 2012) and appeared to be stable expressed by microarray analysis. All primers were obtained from Sigma Genosys (SigmaAldrich Quimica SA, Madrid, Spain). Sequences of the primers used were as follows: $G U S B$, forward: $5^{\prime}$-CCAA GAGCCAGTTCCTCATC-3', reverse: 5'-GGTAGTGGCT GGTACGGAAA-3'; $M M P 23 B$, forward: $5^{\prime}$-GCCTGATG CACTCACAACAC-3', reverse: 5'-GAAGGGGAATTCG TAGCAGA-3'; XYLT2, forward: $5^{\prime}$-CAGCCTCCTGAGG ATGTACC-3', reverse: 5'-TTGTCCCGGTTCTTGGAT AG-3'; HS6ST1, forward: 5'-CAGCAGCGCTACCAGTA CAA-3', reverse: 5'-GGACCTGTCGTCTGTCCTGT-3'; $R P L P O$, forward: 5'-ACAACCCAGCTCTGGAGAAA-3', reverse: 5'-TGCCCCTGGAGATTTTAGTG-3'.

\section{Statistical analysis}

Descriptive results were expressed as mean \pm standard deviation (SD) or percentages, according to the variable being measured. To compare the effects of the two products (test and placebo) on the efficacy of the principal variable, as well as on the main secondary efficacy variables, an analysis of covariance was performed (ANCOVA) with the baseline value as covariate. For the rest of efficacy variables, hypotheses were tested using Fisher's exact test for categorical variables, the Student's $t$ test for continuous variables, and Mann-Whitney $U$ test for ordinal variables. Pearson's correlation coefficient was used to determine the association between the expression pattern of selected genes in peripheral blood and (1) the degree of synovial effusion; (2) pain; and (3) indicators of muscular strength of the affected knee, namely maximum work load, maximum peak torque, and power. The significance level was fixed at $p=0.05$. The SAS 6.10 statistics program (SAS Institute, Inc., Cary, NC, USA) was used for data analysis. The statistical analysis of microarray data has been described in detail in the section referred to microarray data analysis.

\section{Results}

Seventy-seven participants were included in the study. Nine were excluded from the intended-to-treat population 


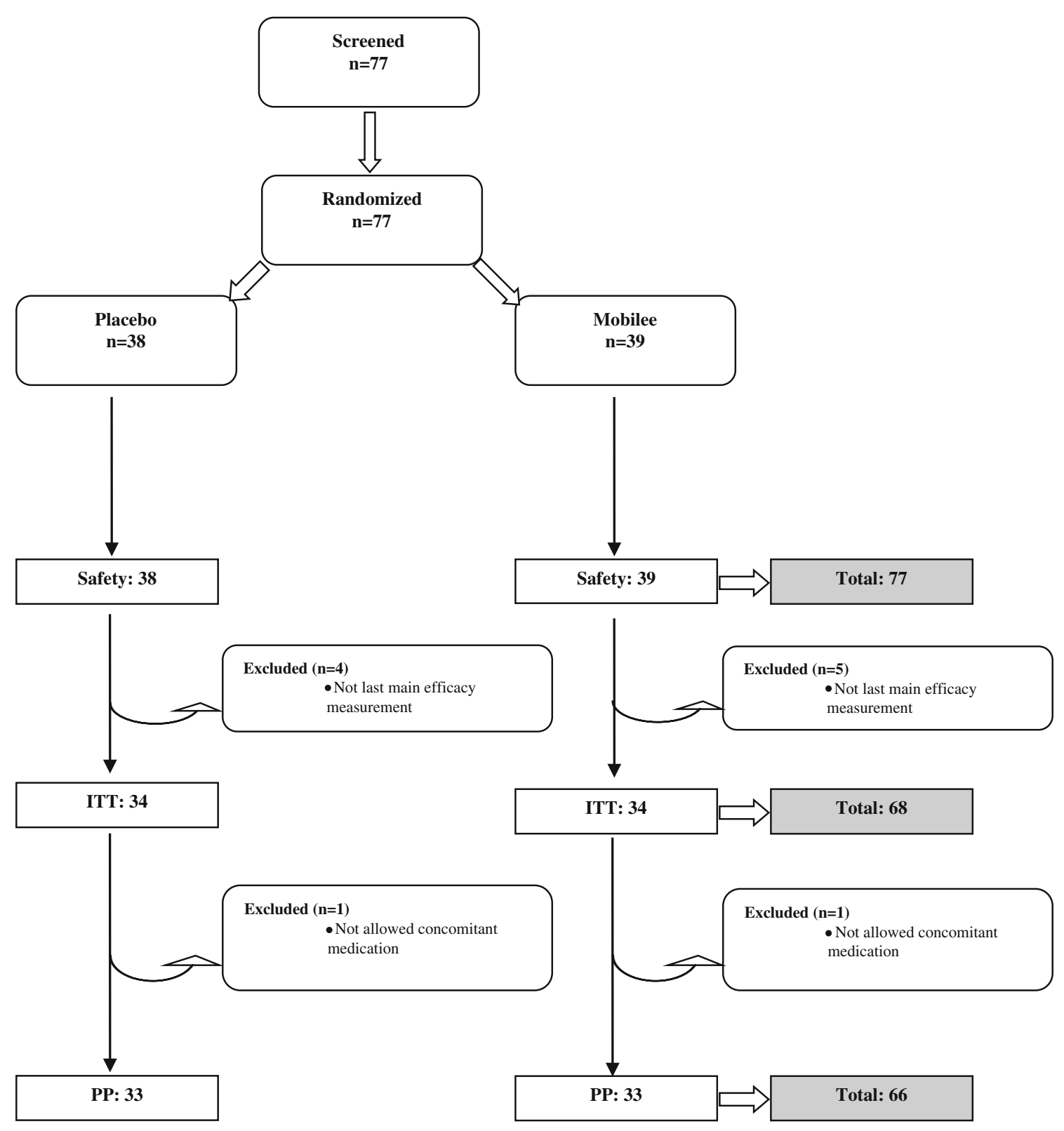

Fig. 1 Disposition of patients and reasons for exclusion

due to the lack of compliance, and two were excluded from protocol population due to protocol violation (Fig. 1). The average age was documented as $54.8 \pm 8.56$ years. There were no significant changes in body weight or clinical parameters (pulse rate, blood pressure) after eating nonsupplemented or supplemented yoghurt (Table 1). Only one participant per group took paracetamol during the whole study period, which is both low and nonsignificantly different.

The daily eating of yoghurt supplemented with $80 \mathrm{mg}$ of Mobilee $^{\mathrm{TM}}$ significantly reduced pain intensity as compared to the eating of yoghurts supplemented with placebo from the second month of treatment $(34.0 \pm 3.85 \mathrm{vs}$.
$32.5 \pm 4.96 \mathrm{~cm} ; p=0.005)$ and specially at the third month $(31.9 \pm 15.81$ vs. $21.1 \pm 12.36 \mathrm{~cm} ; p=0.0005)$ (Fig. 2).

The ultrasonographic assessment revealed a significant reduction in the degree of synovial effusion associated with the eating of yoghurts supplemented with Mobilee ${ }^{\mathrm{TM}}$ as compared to placebo. The total number of participants with a non-physiologic degree of synovial effusion $(>4 \mathrm{~mm})$ was reduced in both groups after 3 months of supplementation. However, the average reduction was of $44 \%$ for the Mobilee $^{\mathrm{TM}}$ group, and $22 \%$ for the placebo group, resulting in significant between-group differences $(p<0.05)$.

As shown in Fig. 3, the mean reduction in the synovial effusion after 3 months of supplementation was double in 
Table 1 Basal characteristics of intended-to-treat population (ITT) population (mean $\pm \mathrm{SD}$ )

\begin{tabular}{llll}
\hline & $\begin{array}{l}\text { Placebo } \\
(n=34)\end{array}$ & $\begin{array}{l}\text { Mobilee }^{\mathrm{TM}} \\
(n=34)\end{array}$ & $p$ value \\
\hline Gender (male/female) & $8 / 26$ & $13 / 21$ & 0.195 \\
Age & $53.6 \pm 8.94$ & $56.1 \pm 8.08$ & 0.458 \\
$\begin{array}{l}\text { Muscular strength of the } \\
\text { affected knee (Nm) (peak } \\
\text { torque, extension at 240\% } \\
\text { s) }\end{array}$ & $64.1 \pm 24.83$ & $65.4 \pm 27.75$ & 0.838 \\
$\begin{array}{l}\text { Degree of synovial effusion } \\
\text { (mm) }\end{array}$ & $3.7 \pm 2.15$ & $4.2 \pm 2.3$ & 0.285 \\
$\begin{array}{l}\text { Pain intensity (cm) } \\
\text { Quality-of-life SF-36 }\end{array}$ & $39.6 \pm 4.86$ & $42.3 \pm 5.67$ & 0.414 \\
$\begin{array}{l}\text { Physic component (PCS- } \\
\quad 36)\end{array}$ & $42.6 \pm 10.26$ & $41.2 \pm 9.34$ & 0.798 \\
$\begin{array}{l}\text { Mental component } \\
\quad \text { MCS-36) }\end{array}$ & $44.9 \pm 12.79$ & $50.1 \pm 8.12$ & 0.194 \\
\hline
\end{tabular}

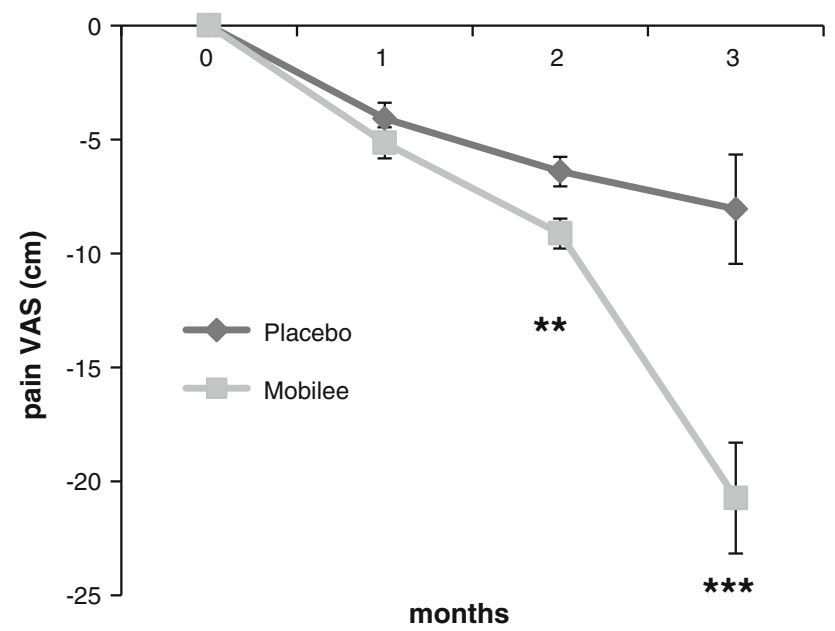

Fig. 2 Time evolution of the pain intensity (VAS). Results are expressed as difference from baseline (mean \pm SEM). Statistics: $* * p<0.01 ; * * * p<0.001$

the Mobilee ${ }^{\mathrm{TM}}$ group than in the placebo group $(-2.7 \pm$ 0.42 vs. $-1.1 \pm 0.54 \mathrm{~mm} ; p=0.041)$.

No differences among SF-36 subscale scores were detected during the study or between treatment groups (Table 2). The primary analysis of isokinetic evaluation of muscular strength of the affected joint in extended position, applying an angle speed of $240^{\circ}$ per second (absolute change from baseline), is detailed in Table 2. No statistical difference was observed after the intervention. The average value increased $1.435 \mathrm{Nm}$ for the Mobilee ${ }^{\mathrm{TM}}$ group and 1.109 for the placebo $(p=0.9064)$. However, the analysis of subpopulations revealed that evolution of muscular strength could be interfered by the basal degree of synovial effusion on the affected knee. At baseline, $53 \%$ of the participants in the placebo group and $47 \%$ in the

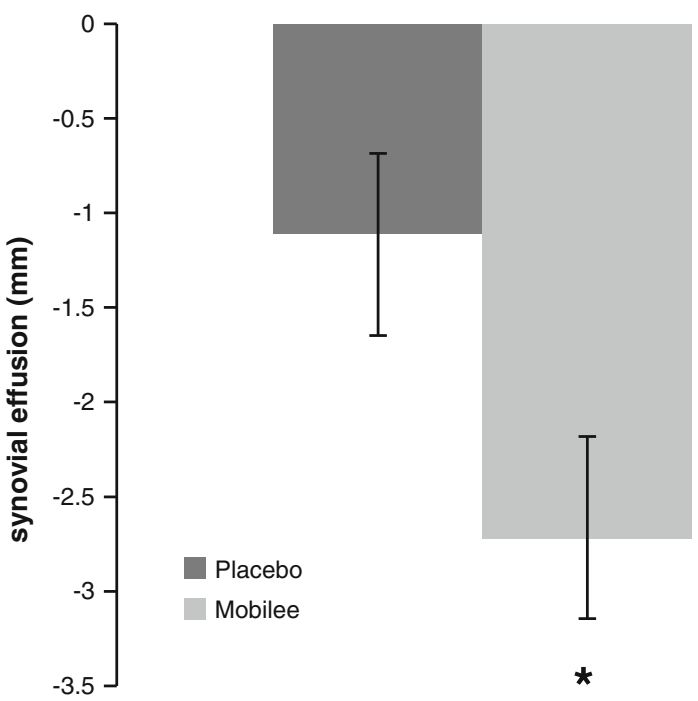

Fig. 3 Degree of synovial effusion after 3 months compared to basal values (mean $\pm \mathrm{SD}$ ). Statistics: $* p<0.05$

Mobilee $^{\text {TM }}$ had an increased level of synovial fluid ( $>4 \mathrm{~mm}$ in the suprapatellar recess). The excess of synovial fluid could produce pain and therefore interfere with isokinetic assessment of the muscular strength. Sub-analysis of the muscular strength evolution excluding those participants with a non-physiologic degree of synovial fluid at baseline indicated differences between groups $(p<0.05)$. In the placebo group, muscular strength was reduced after 3 months of supplementation $(-2.3 \pm$ $2.71 \mathrm{Nm}$ ), while in the Mobilee ${ }^{\mathrm{TM}}$ group, it was increased $(2.9 \pm 1.67 \mathrm{Nm})($ Table 3$)$.

\section{Microarray results}

Of the 43,118 probes tested on the array, 24,640 had an expression value twice above the background and were further taken into account. Of these, 640 probes were differentially expressed between supplemented and placebo groups post-intervention, but not pre-intervention $(p<0.05$; Student's $t$ test). We further restricted the analysis to the differentially expressed probes $(p<0.05)$ with an absolute fold change $\geq 1.2$, resulting in a total of 264 probes representing 206 unique genes. Of these, 49 corresponded to predicted genes with unknown function (43) or to noncoding RNA (6) and 157 corresponded to known protein coding genes. Among the latter, 57 genes exhibited up-regulation and 100 down-regulation in the supplemented group as compared to the placebo group (Supplementary table 1). The fold change in these genes ranged up to 1.96 , an expected small effect since nutritional studies within the physiological range in general result in small differences in transcript levels (Keijer et al. 2010). The 157 
Table 2 Results of the efficacy parameters registered on the intended-to-treat (ITT) population (mean $\pm \mathrm{SD}$, $n=34$ in each group) $p$ values $<0.05$ are highlighted in bold

\begin{tabular}{|c|c|c|c|c|}
\hline Parameter & Basal & 1 month & 2 month & 3 month \\
\hline \multicolumn{5}{|c|}{ Muscular strength (Nm) } \\
\hline \multicolumn{5}{|c|}{ Peak torque, extension at $240 \% \mathrm{~s}$} \\
\hline Placebo & $64.1 \pm 24.83$ & & & $65.3 \pm 23.73$ \\
\hline Mobilee $^{\mathrm{TM}}$ & $65.4 \pm 27.75$ & & & $66.7 \pm 27.12$ \\
\hline$p$ value & & & & 0.906 \\
\hline \multicolumn{5}{|c|}{ Synovial effusion (mm) } \\
\hline Placebo & $3.8 \pm 2.15$ & & & $2.7 \pm 2.80$ \\
\hline Mobilee $^{\mathrm{TM}}$ & $4.2 \pm 2.3$ & & & $1.6 \pm 1.51$ \\
\hline$p$ value & & & & 0.029 \\
\hline \multicolumn{5}{|c|}{ Pain VAS (cm) } \\
\hline Placebo & $39.6 \pm 4.86$ & $36.1 \pm 3.96$ & $34.0 \pm 3.85$ & $31.9 \pm 15.81$ \\
\hline Mobilee $^{\mathrm{TM}}$ & $42.3 \pm 5.67$ & $36.7 \pm 5.99$ & $32.5 \pm 4.96$ & $21.1 \pm 12.36$ \\
\hline$p$ value & & 0.278 & 0.005 & $<0.001$ \\
\hline \multicolumn{5}{|c|}{ Quality-of-life SF-36 } \\
\hline \multicolumn{5}{|c|}{ Physical component (PCS-36) } \\
\hline Placebo & $42.6 \pm 10.26$ & $44.5 \pm 10.95$ & $44.8 \pm 10.56$ & $44.0 \pm 10.62$ \\
\hline Mobilee $^{\mathrm{TM}}$ & $41.2 \pm 9.34$ & $42.9 \pm 8.67$ & $43.4 \pm 9.13$ & $45.5 \pm 9.05$ \\
\hline$p$ value & & 0.727 & 0.824 & 0.093 \\
\hline \multicolumn{5}{|c|}{ Mental component (MCS-36) } \\
\hline Placebo & $44.9 \pm 12.79$ & $47.5 \pm 11.82$ & $47.5 \pm 12.69$ & $49.5 \pm 10.79$ \\
\hline Mobilee $^{\mathrm{TM}}$ & $50.1 \pm 8.12$ & $50.4 \pm 9.59$ & $49.5 \pm 9.97$ & $50.2 \pm 10.68$ \\
\hline$p$ value & & 0.881 & 0.876 & 0.295 \\
\hline
\end{tabular}

Table 3 Absolute values of muscular strength (peak torque) in extension at an angular velocity of $240 \%$ s of the participants without synovial effusion at baseline (mean $\pm \mathrm{SD}, n=34$ in each group)

\begin{tabular}{lll}
\hline $\begin{array}{l}\text { Muscular strength (peak torque, } \\
\text { extension at } 240 \% \text { s) }\end{array}$ & Basal & 3 months \\
\hline Placebo & $57.13 \pm 4.51$ & $54.83 \pm 3.25$ \\
Mobilee $^{\mathrm{TM}}$ & $63.53 \pm 7.82$ & $66.46 \pm 7.46$ \\
$p$ value & & $\mathbf{0 . 0 3 2 4}$ \\
\hline
\end{tabular}

$p$ values $<0.05$ are highlighted in bold

protein-encoding genes were manually annotated to biological processes according to their function. As shown in Fig. 4, the processes with the highest number of differentially expressed genes were related to cell signaling, cell turnover, immune system, transcription and translation, and transport. Strikingly, among the differentially expressed genes, there were 4 genes for proteins well known to be related to GAG metabolism and extracellular matrix dynamics (Table 4). In particular, a lower peripheral blood gene expression of matrix metallopeptidase 23B $(M M P 23 B)$, glucuronidase-beta $(G U S B)$, xylosyltransferase II (XYLT2), and heparan sulfate 6- $O$-sulfotransferase 1 (HS6ST1) was found in the supplemented group postintervention compared to the placebo group. Additionally, RT-qPCR analysis on paired samples pre- and post-intervention indicated a significant reduction in peripheral blood gene expression of $M M P 23 B$ and XYLT2 following Mobilee $^{\mathrm{TM}}$ intervention compared to placebo (Fig. 5); a similar trend was evidenced for GUSB gene expression.

\section{Association studies of gene expression levels in blood cells with articular health-related parameters}

Pearson's correlations were calculated to determine the relationship between the expression levels in blood cells of identified genes related to GAG metabolism and extracellular matrix dynamics possibly affected by Mobilee $^{\mathrm{TM}}$ intervention (GUSB, HS6ST1, MMP23B, XYLT2) and articular health-related parameters (Table 5). The expression levels in blood cells of HS6ST1 and MMP23B showed a strong positive correlation with pain sensation, so that the higher the expression of these two genes, the higher the pain, and vice versa $(r=0.356, p<0.05$ for HS6ST1; and $r=0.522, p<0.001$ for MMP23B). Additionally, HS6STI expression was negatively correlated with all the muscular strength indicators studied in the affected knee, namely peak torque, total work, and mean power at $240 \% \mathrm{~s}(r=-0.368$, -0.351 , and -0.388 , respectively, $p<0.05$ ), so that the lower the HS6ST1 expression, the higher these muscular strength indicators. No significant correlation between peripheral blood expression of prioritised genes and synovial effusion values was detected (data not shown). Pearson's 
Fig. 4 Classification into biological processes of genes that significantly change in Mobilee $^{\mathrm{TM}}$ supplemented versus control group postintervention but not preintervention

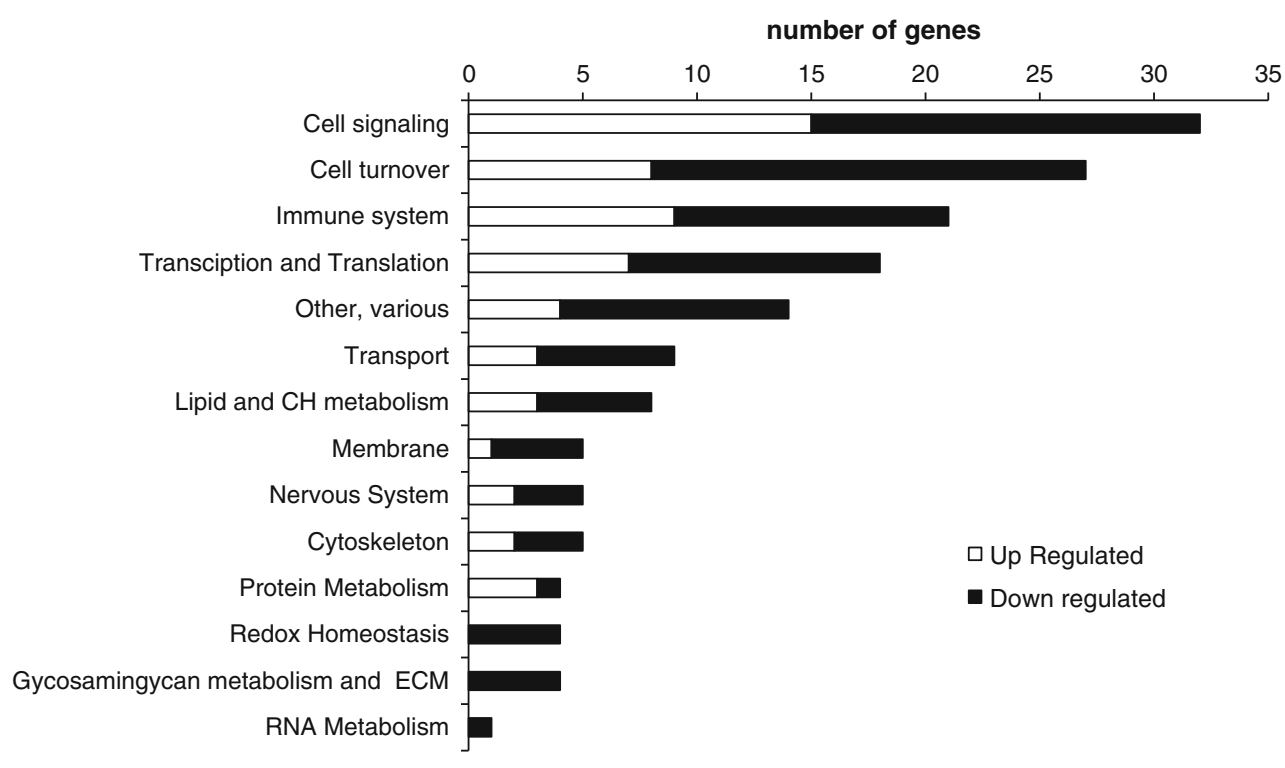

Table 4 Genes related to GAG metabolism and extracellular matrix dynamics differentially expressed between Mobilee ${ }^{\mathrm{TM}}$ and placebo groups post-intervention $(p<0.05)$, but not pre-intervention

\begin{tabular}{|c|c|c|c|c|c|}
\hline Gene & Name & $\begin{array}{l}\text { Systematic } \\
\text { name }\end{array}$ & Function & $\begin{array}{l}\text { Fold change Mobilee }{ }^{\mathrm{TM}} \text { vs. } \\
\text { placebo }\end{array}$ & $p$ value \\
\hline GUSB & Glucuronidase-beta & NM_000181 & Hydrolase that degradates GAG & -1.22 & 0.027 \\
\hline HS6ST1 & $\begin{array}{l}\text { Heparan sulfate 6-O- } \\
\text { sulfotransferase } 1\end{array}$ & NM_004807 & $\begin{array}{l}\text { Enzyme responsible for 6-O-sulfation } \\
\text { of heparan sulfate }\end{array}$ & -1.22 & 0.009 \\
\hline MMP23B & Matrix metallopeptidase 23B & NM_006983 & $\begin{array}{l}\text { Protease involved in the breakdown of } \\
\text { the extracellular matrix }\end{array}$ & -1.30 & 0.028 \\
\hline XYLT2 & Xylosyltransferase II & NM_022167 & $\begin{array}{l}\text { Enzyme that initiates the biosynthesis } \\
\text { of GAGs including chondroitin } \\
\text { sulfate, heparan sulfate, heparin, and } \\
\text { dermantan sulfate in proteoglycans }\end{array}$ & -1.32 & 0.004 \\
\hline
\end{tabular}

correlations gave similar results using either microarray or RT-qPCR gene expression data, further validating them.

\section{Discussion}

Healthy individuals with joint discomfort were enrolled in a prospective nutritional randomized, double-blind, placebo-controlled study. The supplemented group ate one yoghurt containing Mobilee ${ }^{\mathrm{TM}}$ - a rooster comb extract, containing HA (65\%), polysaccharides, and collagen-per day for 90 days. Similar to the outcome of a previous study with another set of volunteers (Martinez-Puig et al. 2013), the daily supplementation with Mobilee $^{\mathrm{TM}}$ significantly reduced pain intensity (one of the primary symptoms of joint discomfort) and the degree of synovial effusion (a clinical finding linked to inflammation) and improved the muscular strength parameters compared to placebo. Here, we were particularly interested in novel and accessible biomarkers of articular health improvement related to Mobilee $^{\mathrm{TM}}$ intake. For this purpose, whole-genome microarray analysis was performed on blood samples from a subset of 20 women (OA frequently affects middle-age women (Das and Farooqi 2008)), 10 non-supplemented, and 10 supplemented with Mobile ${ }^{\mathrm{TM}}$. On the basis of their differential expression in Mobile ${ }^{\mathrm{TM}}$ and placebo groups post-intervention and of correlations detected with articular pain and affected muscle strength indicators, we propose gene expression of 4 proteins in GAG metabolism and extracellular matrix remodeling-GUSB, HS6ST1, $M M P 23 B$, and $X Y L T 2$ - as potential blood cell transcriptbased biomarkers of beneficial joint responsiveness to the tested oral intervention.

Blood cells travel through the body and are able to respond to internal and external signals. Studies indicate that blood cells can reflect gene expression signatures characteristic of different nutritional conditions, physiological disorders, or diseases (Caimari et al. 2010; 
Fig. 5 Percentage of change in the expression of matrix metallopeptidase 23B $(M M P 23 B)$, xylosyltransferase II (XYLT2), glucuronidase-beta $(G U S B)$, and heparan sulfate 6- $O$-sulfotransferase 1 (HS6ST1), on paired samples pre- and post-intervention, analyzed by qRT-PCR, compared to basal values. Statistics: $* p<0.05$, Student's $t$ test percentage of change MMP23B

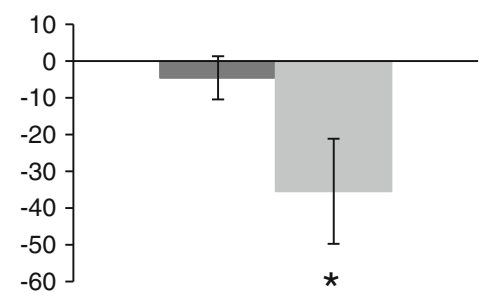

percentage of change GUS

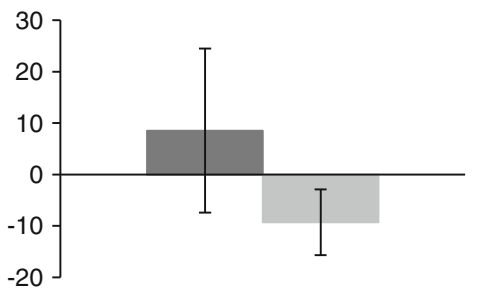

percentage of change XYLT2

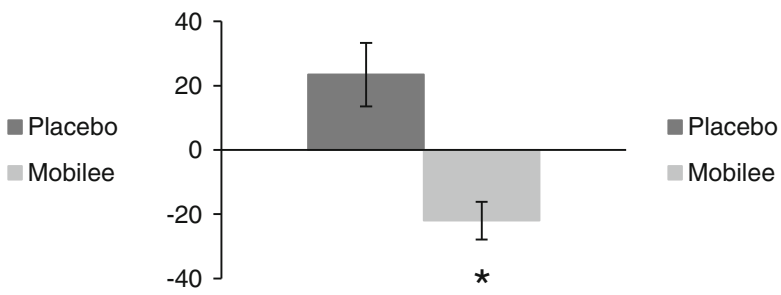

percentage of change HS6ST1

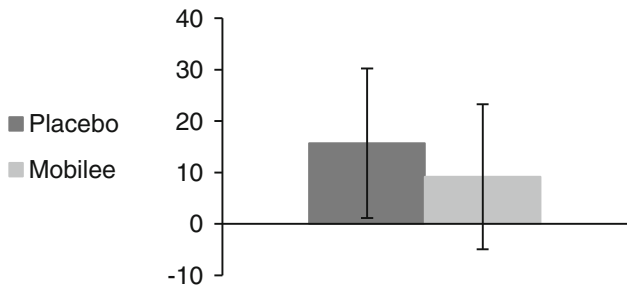

Placebo

Mobilee

Table 5 Pearson's correlations between expression levels in blood cells of identified genes related to GAG metabolism and extracellular matrix dynamics with pain and muscular strength indicators of the affected knee

\begin{tabular}{llllll}
\hline Gene & Name & Pain & Peak torque at $240^{\circ} / \mathrm{s}$ & Total work at $240^{\circ} / \mathrm{s}$ & Mean power at $240^{\circ} / \mathrm{s}$ \\
\hline GUSB & Glucuronidase-beta & n.s & n.s & n.s & n.s \\
HS6ST1 & Heparan sulfate 6- $O$-sulfotransferase 1 & $0.356^{*}$ & $-0.368^{*}$ & $-0.351^{*}$ & $-0.388^{*}$ \\
MMP23B & Matrix metallopeptidase 23B & $0.522^{* * *}$ & n.s & n.s & n.s \\
XYLT2 & Xylosyltransferase II & n.s & n.s & n.s & n.s \\
\hline
\end{tabular}

n.s not significant. $* p<0.05 ; * * * p<0.001$

Oliver et al. 2013) and references therein). In particular, because OA can be regarded as a systemic disorder in which circulating blood cells (such as macrophages and $\mathrm{T}$ cells) accumulate in synovial tissues, subsequently resulting in cartilage degeneration and alterations of subchondral bone (Sakkas and Platsoucas 2007), it is conceivably that, even in preclinical stages, gene expression in blood cells can both affect and reflect changes occurring in joint tissues. In fact, changes in microRNA expression in peripheral mononuclear cells according to the progression of OA have been reported (Okuhara et al. 2012), as well as differences in peripheral blood gene expression signature between $\mathrm{OA}$ cases and controls concerning genes related to apoptotic pathways (Ramos et al. 2013), pro-inflammatory cytokine expression (IL-1 $\beta$ ) (Attur et al. 2011), and the expression of key bone-regulatory factors (bone morphogenetic proteins and Runx2) (Grcevic et al. 2010). Furthermore, changes in peripheral white blood cells gene expression signature during the course of experimentally induced OA have been documented in the horse (Kamm et al. 2013). Investigating biomarkers in the context of specific OA therapeutic treatments is considered a good strategy toward biomarker discovery (Kraus et al. 2011). So far, transcriptome modification of white blood cells after dietary administration of curcumin and nonsteroidal anti-inflammatory drug has been assessed in OA affected dogs (Colitti et al. 2012). The present work is, to our knowledge, first to apply this strategy to OA research or articular discomfort research in healthy humans.

At the end of the intervention period, but not prior intervention, subjects in the Mobilee ${ }^{\mathrm{TM}}$ group presented decreased expression levels of GUSB, HS6ST1, MMP23B, and XYLT2 in blood cells compared to subjects in the control, placebo group. Interestingly, we found a strong correlation between the expression of $M M P 23 B$ and HS6ST1 with pain and indicators of muscular strength. In particular, correlation analysis indicated that the lower the expression of $M M P 23 B$ and HS6ST1, the lower the pain intensity, and the lower the expression of HS6ST1, the higher the indicators of knee muscular strength. Thus, it is suggested that decreased transcript levels of these genes may be indicative of an improvement or an amelioration of joint disease progression associated with Mobilee $^{\mathrm{TM}}$ consumption. 
Interestingly, the four prioritized genes encode proteins previously related to joint diseases and specifically to OA in a manner that suggests that down-regulation of its expression may be beneficial. GUSB is a lysosomal enzyme involved in the degradation of GAGs that plays an essential role in the remodeling of the extracellular matrix components in both physiological and inflammatory states (Naz et al. 2013). Increased GUSB activity (along with that of other glycosidases) is present in the synovial fluid of patients with rheumatoid arthritis (Ortutay et al. 2003) and OA (Kamada et al. 1993). HS6ST is an enzyme involved in heparan sulfate biosynthesis whose activity has recently been linked to the up-regulation of certain mast cell proteases such as tryptase (but not chymase) (Anower et al. 2013). Activation of synovial mast cells proteases, and specifically tryptase, is a factor in the pathogenesis of both rheumatoid arthritis and OA (Buckley et al. 1998; Shin et al. 2009; de Lange-Brokaar et al. 2012). Proteins from the matrix metalloproteinase (MMP) family are responsible for cartilage collagen breakdown and have long been associated with the pathogenesis of OA (Lee et al. 2013; Troeberg and Nagase 2012). The literature is replete with evidences of MMP1, 3,9 , and 13 in the development of OA (reviewed in (Lee et al. 2013). Although less information is there regarding MMP23B, its involvement is suggested by the fact that MMP23 expression is up-regulated in the synovium and the cartilage of patients with OA of the hip compared with patients with fracture to the neck of femur, which were used as controls (Davidson et al. 2006). XYLT2 is one of two xylosyltransferases (XYLTs) that catalyze the initial and rate-limiting step in the biosynthesis of GAGs (Gotting et al. 2007; Muller et al. 2013). High XYLT activity in synovial fluids of patients with rheumatoid arthritis has been reported, attributed to increased cartilage destruction during the course of this disease (Kleesiek et al. 1987). Moreover, serum XYLT activity is elevated in serum of woman with OA as compared to controls (Schon et al. 2006), and nonsteroidal anti-inflammatory drugs used in the treatment of OA have been shown to reduce XYLT activity in human osteoarthritic cartilage in vitro (David et al. 1992).

Overall, this study evidences that expression levels of specific genes in peripheral blood cells, in particular genes related to GAG metabolism and extracellular matrix dynamics, are potential biomarkers of beneficial effects of functional foods for articular health.

Acknowledgments The research leading to these results has been funded in part by the European Union's Seventh Framework Programme FP7 2007-2013 under Grant Agreement No 244995 (BIOCLAIMS Project). It has also been supported through a contract with Bioiberica S.A. within the framework of the CENIT-2008-1004 PRONAOS project of the Spanish Government.
Conflict of interest JS, MLB, JK, EMvS, IM, and AP have no conflict of interest, financial or scientific. DMP and CC are employed by Bioiberica S.A., Palafolls, Barcelona, Spain, the supplier of Mobilee $^{\text {TM }}$. Bioiberica S.A., Palafolls, Barcelona, Spain, had no role in the scientific interpretation of the results and did not influence the way these results were reported.

Ethical standard All procedures followed were in accordance with the principles of the Declaration of Helsinki. All the participants gave their informed consent for the study, and the Fundació Gol i Gurina Ethical Review Committee approved the study protocol.

\section{References}

Allison DB, Cui X, Page GP, Sabripour M (2006) Microarray data analysis: from disarray to consolidation and consensus. Nat Rev Genet 7(1):55-65. doi:10.1038/nrg 1749

Altman RD, Moskowitz R (1998) Intraarticular sodium hyaluronate (Hyalgan) in the treatment of patients with osteoarthritis of the knee: a randomized clinical trial. Hyalgan Study Group. J Rheumatol 25(11):2203-2212

Anower EKMF, Habuchi H, Nagai N, Habuchi O, Yokochi T, Kimata K (2013) Heparan sulfate 6-O-sulfotransferase isoform-dependent regulatory effects of heparin on the activities of various proteases in mast cells and the biosynthesis of 6-O-sulfated heparin. J Biol Chem 288(6):3705-3717. doi:10.1074/jbc.M112.416651

Attur M, Belitskaya-Levy I, Oh C, Krasnokutsky S, Greenberg J, Samuels J, Smiles S, Lee S, Patel J, Al-Mussawir H, McDaniel G, Kraus VB, Abramson SB (2011) Increased interleukin-1beta gene expression in peripheral blood leukocytes is associated with increased pain and predicts risk for progression of symptomatic knee osteoarthritis. Arthritis Rheum 63(7):1908-1917. doi:10. 1002/art.30360

Balogh L, Polyak A, Mathe D, Kiraly R, Thuroczy J, Terez M, Janoki G, Ting Y, Bucci LR, Schauss AG (2008) Absorption, uptake and tissue affinity of high-molecular-weight hyaluronan after oral administration in rats and dogs. J Agric Food Chem 56(22):10582-10593. doi:10.1021/jf8017029

Bonet ML, Granados N, Palou A (2011) Molecular players at the intersection of obesity and osteoarthritis. Curr Drug Targets 12(14):2103-2128. doi:10.2174/138945011798829393

Buckley MG, Gallagher PJ, Walls AF (1998) Mast cell subpopulations in the synovial tissue of patients with osteoarthritis: selective increase in numbers of tryptase-positive, chymasenegative mast cells. J Pathol 186(1):67-74. doi:10.1002/ (SICI)1096-9896(199809)186:1<67:AID-PATH132>3.0.CO;2-D

Caimari A, Oliver P, Keijer J, Palou A (2010) Peripheral blood mononuclear cells as a model to study the response of energy homeostasis-related genes to acute changes in feeding conditions. OMICS 14(2):129-141. doi:10.1089/omi.2009.0092

D'Agostino MA, Conaghan P, Le Bars M, Baron G, Grassi W, Martin-Mola E, Wakefield R, Brasseur JL, So A, Backhaus M, Malaise M, Burmester G, Schmidely N, Ravaud P, Dougados M, Emery P (2005) EULAR report on the use of ultrasonography in painful knee osteoarthritis. Part 1: prevalence of inflammation in osteoarthritis. Ann Rheum Dis 64(12):1703-1709. doi:10.1136/ $\operatorname{ard} .2005 .037994$

Das SK, Farooqi A (2008) Osteoarthritis. Best Pract Res Clin Rheumatol 22(4):657-675. doi:10.1016/j.berh.2008.07.002

David MJ, Vignon E, Peschard MJ, Broquet P, Louisot P, Richard M (1992) Effect of non-steroidal anti-inflammatory drugs (NSAIDS) on glycosyltransferase activity from human osteoarthritic cartilage. Br J Rheumatol 31(Suppl 1):13-17 
Davidson RK, Waters JG, Kevorkian L, Darrah C, Cooper A, Donell ST, Clark IM (2006) Expression profiling of metalloproteinases and their inhibitors in synovium and cartilage. Arthritis Res Ther 8(4):R124. doi:10.1186/ar2013

de Lange-Brokaar BJ, Ioan-Facsinay A, van Osch GJ, Zuurmond AM, Schoones J, Toes RE, Huizinga TW, Kloppenburg M (2012) Synovial inflammation, immune cells and their cytokines in osteoarthritis: a review. Osteoarthr Cartil 20(12):1484-1499. doi:10.1016/j.joca.2012.08.027

Dheda K, Huggett JF, Bustin SA, Johnson MA, Rook G, Zumla A (2004) Validation of housekeeping genes for normalizing RNA expression in real-time PCR. Biotechniques 37(1):112-114

Dougados M, Nguyen M, Listrat V, Amor B (1993) High molecular weight sodium hyaluronate (hyalectin) in osteoarthritis of the knee: a 1 year placebo-controlled trial. Osteoarthr Cartil OARS Osteoarthr Res Soc 1(2):97-103. doi:10.1016/S1063-4584(05) 80024-X

EFSA (2013) Panel on Dietetic Products. Nutrition and Allergies (NDA); scientific opinion on Rooster Combs Extract. EFSA J 11(6):3260. doi:10.2903/j.efsa.2013.3260

Goldring MB, Goldring SR (2007) Osteoarthritis. J Cell Physiol 213(3):626-634. doi:10.1002/jcp.21258

Gotting C, Kuhn J, Kleesiek K (2007) Human xylosyltransferases in health and disease. Cell Mol Life Sci 64(12):1498-1517. doi:10. 1007/s00018-007-7069-z

Grcevic D, Jajic Z, Kovacic N, Lukic IK, Velagic V, Grubisic F, Ivcevic S, Marusic A (2010) Peripheral blood expression profiles of bone morphogenetic proteins, tumor necrosis factor-superfamily molecules, and transcription factor Runx 2 could be used as markers of the form of arthritis, disease activity, and therapeutic responsiveness. J Rheumatol 37(2):246-256. doi:10.3899/jrheum.090167

Kamada A, Fujita A, Kakudo K, Okazaki J, Ida M, Sakaki T (1993) Changes in synovial fluid $\mathrm{N}$-acetyl-beta-glucosaminidase activity in the human temporomandibular joint with dysfunction. J Osaka Dent Univ 27(2):107-111

Kamm JL, Frisbie DD, McIlwraith CW, Orr KE (2013) Gene biomarkers in peripheral white blood cells of horses with experimentally induced osteoarthritis. Am J Vet Res 74(1):115-121. doi:10.2460/ajvr.74.1.115

Keijer J, van Helden YG, Bunschoten A, van Schothorst EM (2010) Transcriptome analysis in benefit-risk assessment of micronutrients and bioactive food components. Mol Nutr Food Res 54(2):240-248. doi:10.1002/mnfr.200900304

Kleesiek K, Reinards R, Okusi J, Wolf B, Greiling H (1987) UDP-Dxylose: proteoglycan core protein beta-D-xylosyltransferase: a new marker of cartilage destruction in chronic joint diseases. J Clin Chem Clin Biochem 25(8):473-481

Kraus VB, Burnett B, Coindreau J, Cottrell S, Eyre D, Gendreau M, Gardiner J, Garnero P, Hardin J, Henrotin Y, Heinegard D, Ko A, Lohmander LS, Matthews G, Menetski J, Moskowitz R, Persiani S, Poole AR, Rousseau JC, Todman M (2011) Application of biomarkers in the development of drugs intended for the treatment of osteoarthritis. Osteoarthr Cartil 19(5): 515-542. doi:10.1016/j.joca.2010.08.019

Lee AS, Ellman MB, Yan D, Kroin JS, Cole BJ, van Wijnen AJ, Im HJ (2013) A current review of molecular mechanisms regarding osteoarthritis and pain. Gene 527(2):440-447. doi:10.1016/j. gene.2013.05.069

Martinez-Puig D, Möller I, Fernández C, Chetrit C (2013) Efficacy of oral administration of yoghurt supplemented with a preparation containing hyaluronic acid (Mobile ${ }^{\mathrm{TM}}$ ) in adults with mild joint discomfort: a randomized, double-blind, placebo-controlled intervention study. Med J Nutr Metab 6(1):63-68. doi:10.1007/ s12349-012-0108-9

Martínez-Puig D, Carmona J, Arguelles D, Deulofeu R, A Ubia, Prades M (2007) Oral hyaluronic acid administration improves osteochondrosis clinical symptoms and slightly increases intraarticular concentration of hyaluronic acid in a horse model: a pilot survey. Osteoarthr Cartil 15:C62-C63. doi:10.1016/S10634584(07)61729-4

McHorney CA, Ware JE Jr, Raczek AE (1993) The MOS 36-Item Short-Form Health Survey (SF-36): II. Psychometric and clinical tests of validity in measuring physical and mental health constructs. Med Care 31(3):247-263

Muller B, Prante C, Knabbe C, Kleesiek K, Gotting C (2013) First identification and functional analysis of the human xylosyltransferase II promoter. Glycoconj J 30(3):237-245. doi:10.1007/ s10719-012-9439-5

Naz H, Islam A, Waheed A, Sly WS, Ahmad F, Hassan MI (2013) Human beta-glucuronidase: structure, function, and application in enzyme replacement therapy. Rejuvenation Res 16(5): 352-363. doi:10.1089/rej.2013.1407

Okuhara A, Nakasa T, Shibuya H, Niimoto T, Adachi N, Deie M, Ochi M (2012) Changes in microRNA expression in peripheral mononuclear cells according to the progression of osteoarthritis. Mod Rheumatol 22(3):446-457. doi:10.1007/s10165-011-0536-2

Oliver P, Reynes B, Caimari A, Palou A (2013) Peripheral blood mononuclear cells: a potential source of homeostatic imbalance markers associated with obesity development. Pflugers Arch 465(4):459-468. doi:10.1007/s00424-013-1246-8

Ortutay Z, Polgar A, Gomor B, Geher P, Lakatos T, Glant TT, Gay RE, Gay S, Pallinger E, Farkas C, Farkas E, Tothfalusi L, Kocsis K, Falus A, Buzas EI (2003) Synovial fluid exoglycosidases are predictors of rheumatoid arthritis and are effective in cartilage glycosaminoglycan depletion. Arthritis Rheum 48(8):21632172. doi:10.1002/art.11093

Pellis L, Franssen-van Hal NL, Burema J, Keijer J (2003) The intraclass correlation coefficient applied for evaluation of data correction, labeling methods, and rectal biopsy sampling in DNA microarray experiments. Physiol Genomics 16(1):99-106. doi:10.1152/physiolgenomics.00111.2003

Pfaffl MW (2001) A new mathematical model for relative quantification in real-time RT-PCR. Nucleic Acids Res 29(9):e45. doi:10.1093/nar/29.9.e45

Rainen L, Oelmueller U, Jurgensen S, Wyrich R, Ballas C, Schram J, Herdman C, Bankaitis-Davis D, Nicholls N, Trollinger D, Tryon V (2002) Stabilization of mRNA expression in whole blood samples. Clin Chem 48(11):1883-1890

Ramonda R, Frallonardo P, Musacchio E, Vio S, Punzi L (2013) Joint and bone assessment in hand osteoarthritis. Clin Rheumatol. doi:10.1007/s10067-013-2404-2

Ramos YF, Bos SD, Lakenberg N, Bohringer S, den Hollander WJ, Kloppenburg M, Slagboom PE, Meulenbelt I (2013) Genes expressed in blood link osteoarthritis with apoptotic pathways. Ann Rheum Dis. doi:10.1136/annrheumdis-2013-203405

Rousseau J, Garnero P (2012) Biological markers in osteoarthritis. Bone 51(2):265-277. doi:10.1016/j.bone.2012.04.001

Sakkas LI, Platsoucas CD (2007) The role of $T$ cells in the pathogenesis of osteoarthritis. Arthritis Rheum 56(2):409-424. doi: 10.1002/art.22369

Sanchez J, Palou A, Pico C (2009) Response to carbohydrate and fat refeeding in the expression of genes involved in nutrient partitioning and metabolism: striking effects on fibroblast growth factor-21 induction. Endocrinology 150(12):5341-5350. doi:10. 1210/en.2009-0466

Sanchez J, Priego T, Pico C, Ahrens W, De Henauw S, Fraterman A, Marild S, Molnar D, Moreno LA, Peplies J, Russo P, Siani A, Tornaritis M, Veidebaum T, Palou A (2012) Blood cells as a source of transcriptional biomarkers of childhood obesity and its related metabolic alterations: results of the IDEFICS study. J Clin Endocrinol Metab 97(4):E648-E652. doi:10.1210/jc. 2011-2209 
Schon S, Huep G, Prante C, Muller S, Christ R, Hagena FW, Kuhn J, Kleesiek K, Gotting C (2006) Mutational and functional analyses of xylosyltransferases and their implication in osteoarthritis. Osteoarthr Cartil 14(5):442-448. doi:10.1016/j.joca.2005.11.004

Shin K, Nigrovic PA, Crish J, Boilard E, McNeil HP, Larabee KS, Adachi R, Gurish MF, Gobezie R, Stevens RL, Lee DM (2009) Mast cells contribute to autoimmune inflammatory arthritis via their tryptase/heparin complexes. J Immunol 182(1):647-656. doi:10.4049/jimmunol.182.1.647

Tashiro T, Seino S, Sato T, Matsuoka R, Masuda Y, Fukui N (2012) Oral administration of polymer hyaluronic acid alleviates symptoms of knee osteoarthritis: a double-blind, placebocontrolled study over a 12-month period. Sci World J 2012:167928. doi:10.1100/2012/167928
Troeberg L, Nagase H (2012) Proteases involved in cartilage matrix degradation in osteoarthritis. Biochim Biophys Acta 1824(1): 133-145. doi:10.1016/j.bbapap.2011.06.020

van Schothorst EM, Pagmantidis V, de Boer VC, Hesketh J, Keijer J (2007) Assessment of reducing RNA input for Agilent oligo microarrays. Anal Biochem 363(2):315-317. doi:10.1016/j.ab. 2007.01.016

Yang YH, Dudoit S, Luu P, Lin DM, Peng V, Ngai J, Speed TP (2002) Normalization for cDNA microarray data: a robust composite method addressing single and multiple slide systematic variation. Nucleic Acids Res 30(4):e15. doi:10.1093/nar/30. 4.e15 